\title{
Central Immune Senescence, Reversal Potentials
}

\author{
Krisztian Kvell and Judit E. Pongracz \\ Department of Medical Biotechnology, University of Pecs,
}

Hungary

\section{Introduction}

\subsection{Ageing in focus}

Ageing is a complex process that affects all living organisms. Senescence is not only conceivable in multicellular organisms, but also in unicellulars. Unlike certain diseases that have specific morbidity rates, ageing is a physiological process that affects all individuals that live long enough (unaffected by i.e. predation or famine) to experience senescence.

A pioneer of ageing research, August Weismann has established two rather opposing concepts for aging and even today both gather numerous followers. One is the adaptive concept, according to which ageing has evolved to cleanse the population from old, nonreproductive consumers. The other, non-adaptive concept suggests that ageing is due to greater weight on early survival / reproduction rather than vigour at later ages. This latter has been reshaped by the theory of antagonistic pleiotropy (Ljubuncic et al. 2009).

Due to advances in biomedical research and care, currently an average 55-aged person is expected to live up to 85 years of age at death on average in the Western societies. This number is expected to increase if biomedical research continues to develop at the current rate and by the year 2030 an average 55-aged person is expected to live up to 115 years of age at death (according to SENS plans) (de Grey 2007). If such forecasts prove to be true, it is of extraordinary significance and will likely trigger immense social and economical conflicts.

\subsubsection{Ageing and society}

Ageing of the population is one of the most important challenges for the developed world to face over the next decades. The current demographic trends and consequent shrinkage of the active workforce will put enormous pressure on the financing of social protection and health systems, likely to reduce living standards. Taken together with increased migration and emergence of novel infectious diseases, broad-scale provision of immunological protection constitutes a strategic aim for longer and healthier lifespan.

At present life-span is still significantly increasing in the Western civilisations, however, this increase is not accompanied by proportional increase in life spent in overall good health referred to as 'health-span'. There are current efforts to prolong health-span within expanding life-span. This would not only extend life spent in appropriate quality of life, but 
also has the potential to alleviate pressure on current public health systems. This chapter focuses on central immune senescence and therefore will enumerate potential mechanisms of extending human central immune fitness in the elderly.

\subsubsection{Ageing of the immune system}

Impaired immunological responsiveness in the elderly poses a major difficulty. The immunological competence of an individual is determined by the presence of mature lymphocytes formed in primary lymphoid organs, and specialized secondary lymphoid tissues performing diverse immune responses. Thus at systems level the maintenance of immunological equilibrium requires steady lymphocyte output, and controlled expansion. Lymphostromal interactions in both primary and secondary lymphoid tissues play essential roles in the development and function of lymphocyte subsets in adaptive immune responses. The thymic and lymph-node stromal microenvironments thus represent key elements in the development of the adaptive immune system. Consequently, impairment of the lymphoid microenvironment will ultimately lead to insufficient primary and secondary immune responses or to the decline of thymic selection, manifesting in immune senescence accompanied by late-onset autoimmune disorders, often observed in elderly. Self-tolerant cytotoxic and helper T-lymphocytes, the crucial regulator cells in adaptive immune responses, develop in the specialized epithelial network of the thymus. The thymus, however, gradually loses its capacity to support lymphopoiesis in an involution process that results in a decline of de novo T-cell production.

\subsubsection{Significance of thymic involution studies}

In contrast to the extensive studies addressing haemopoietic cells, the in-depth analysis of determinants for stromal competence during immunological ageing is far less detailed, despite its clear significance related to immunological responsiveness in the elderly. There is literature describing quantitative changes that occur during immunological senescence in peripheral immunologically competent tissues like the spleen or lymph nodes. Probably the best characterised, significant example is that of FDCs. Compared to young counterparts the aged follicular dendritic cells express significantly less CD21 ligand and Fc $\gamma$ RII. As a consequence aged FDCs lose their ability to trap immune complexes and present antigens to $B$ cells. This in turn leads to impaired germinal centre reactions and antibody production (Aydar et al. 2004). However, even these well characterised quantitative changes of the peripheral lymphoid tissues are less dramatic than the adipose involution of the thymus.

The manipulation of thymic immune senescence and the restoration of de-novo T-cell production should provide direct benefits for both adult and elderly patients. Such interventions shall increase health-span within life-span significantly reducing the healthcare costs alleviating the burden on healthcare systems.

\subsection{T-cell development in the thymus}

T-cell progenitors migrate to the thymus from the bone marrow where they undergo an extensive differentiation and selection process. After entering the thymus, thymocytes representing different stages of development occupy distinct regions of the thymus. The earliest $\mathrm{CD} 4-\mathrm{CD} 8-\mathrm{CD} 44^{+} \mathrm{CD} 25^{-}$thymocyte progenitors, referred to as double negative 1 
(DN1) cells are found near their site of entry at the cortico-medullary junction. The slightly more mature $\mathrm{CD} 4-\mathrm{CD} 8-\mathrm{CD} 44^{+} \mathrm{CD} 25^{+}(\mathrm{DN} 2)$ subset is found throughout the cortex, whereas CD4-CD8-CD44-CD25+ (DN3) subset is concentrated below the capsule. Following rearrangement of antigen receptor (TCR) genes (He et al. 2006) $\mathrm{CD}^{+}{ }^{+} \mathrm{CD} 8^{+}$(double positive or DP) thymocytes undergo positive (functional TCR) and negative (non self-reactive TCR) selection in the cortex and medulla, to finally leave the thymus for the periphery as CD4$\mathrm{CD}^{+}$(cytotoxic) or $\mathrm{CD}^{+}{ }^{+} \mathrm{CD} 8$ - (helper) single positive (SP), mature, naïve T-cells.

\subsection{Thymic microenvironment in de novo T-cell production}

Successful T-cell development requires the interaction of thymocytes with the thymic stroma, creating the special thymic microenvironment for T-cell differentiation and selection. A large proportion of the thymic stroma consists of epithelial cells that develop from the epithelial thymic anlage from the third pharyngeal pouch around embryonic day 10-11 in the mouse (Manley 2000). Following several differentiation steps, including expression of FoxN1 - a member of the forkhead transcription factor family (Mandinova et al. 2009) - that is essential for Mts24+ epithelial progenitors (Bennett et al. 2002; Gill et al. 2002) to develop into various epithelial subsets (Dooley et al. 2005) and to establish the special thymic epithelial cell phenotype (Manley 2000). FoxN1 expression in early stages of thymus organogenesis is regulated by secreted Wnt4 (Balciunaite et al. 2002) protein. The mature thymic epithelium consists of two major compartments, the cortex and the medulla, which apart from producing chemokines that attract haematopoietic stem cells to the thymus, also contribute the establishing the special thymic microenvironment. The thymic epithelial network regulates homing, intrathymic migration, and differentiation of developing T-lymphocytes through release of cytokines (e.g. interleukin-7 (Alves et al. 2009)), secretion of extracellular matrix components, and establishment of intercellular connections (Crisa L et al. 1996) (Schluns et al. 1997). Thymocytes bearing diverse TCR repertoire are selected by MHC (major-histocompatibility-complex) molecules and MHC bound-antigens presented by the thymic stroma, including epithelial cells. During T-cell development, characterised by progression through phenotypically distinct stages (Lind et al. 2001), thymocytes reside in spatially restricted domains of the mature thymus. T-cell precursors enter the thymus at the cortico-medullary junction (Blackburn et al. 2004), then migrate to the subcapsular zone of the outer cortex, back through the cortex, then to the medulla, where they finally leave to the periphery (Blackburn et al. 2004). Functional studies have shown, that the cortex is important in producing chemokines, which attract prothymocytes (Bleul et al. 2000) and are also essential for mediating positive selection (Anderson et al. 1994). Meanwhile the medullary epithelium has been implicated in driving the final stages of thymocyte maturation (Ge et al. 2000) and has a crucial role in tolerance induction (Farr et al. 1998; Derbinski et al. 2001). Additionally, the thymic epithelium is also the source of other secreted and cell surface proteins that regulate T-cell development. These proteins include bone morphogenic protein (BMP) (Bleul et al. 2005), Notch (Valsecchi 1997), and Wnt (Pongracz et al. 2003) family members.

\subsection{Thymic involution during ageing}

In comparison to other organs, ageing of the thymus is an accelerated process in all mammals. In humans, thymic senescence begins early, around late puberty and by 50 years 
of age $80 \%$ of the thymic stroma is converted into adipose tissue (Dixit 2010). As the thymic epithelium is replaced by adipose tissue, the whole process is called adipose involution (Marinova 2005). Due to decrease in functional thymic epithelial tissue mass, the thymus can no longer support the same output of naïve T-cell production (Ribeiro et al. 2007). Tlymphocyte composition in the periphery therefore exhibits the dominance of memory Tlymphocytes resulting in impaired responses towards novel, particularly viral infections (Chidgey et al. 2007; Gui et al. 2007; Grubeck-Loebenstein 2009). Since the thymic epithelium has also a key role in deleting auto-reactive T-cell clones, functional impairment increases the chances of developing auto-immune disease (Hsu et al. 2003). The transcription factor FoxN1, characteristic in thymus development is also affected by age. FoxN1 (Mandinova et al. 2009) is not only essential for progenitor epithelial cells of the thymic rudiment to develop into various epithelial subsets (Dooley et al. 2005) but also to maintain TEC identity in the differentiated, adult thymus. Decreased level of FoxN1 expression in adult TECs results in accelerated thymic involution (Chen et al. 2009; Cheng et al. 2010).

\subsection{Thymic involution: developmental programme or senescence?}

It has long been known that the thymus begins adipose involution and senescence rather early, but how early is that exactly? Recent studies have analysed the kinetics of thymic function and thymic mass versus age. It has been confirmed in both mouse and human thymic samples that the functional peek of thymic activity significantly precedes the peek of thymic mass and the first signs of adipose involution. In the mouse thymic activity is largely decreased by the age of one month compared to the newborn age (thymocyte precursor immigration at $6 \%$ and mature $\mathrm{T}$ cell emigration at $7 \%$ where $100 \%$ is measured at newborn age), yet the thymus reaches its largest size at one month of age (Shiraishi et al. 2003). Similar tendency has been described in humans where thymic function reaches its peak around the age of one year followed by the first signs of adipose infiltration by the age of approx. five years (Shiraishi et al. 2003). However, most studies describe significant thymic adipose involution starting around puberty / young adulthood. Therefore there is apparently significant detachment of thymic activity peak and thymic mass peak, and surprisingly activity peak significantly precedes mass peak.

The above described phenomenon raises the issue whether the early appearance of thymic involution belongs to senescence or developmental programme and how strictly these two may be separated? Similar questions are raised by the detection of miniature atherosclerotic lesions detected already at foetal age, a currently fashionable topic (Leduc et al. 2010).

\subsection{Trans-differentiation of fibroblasts into adipocytes}

The nuclear lamina consists of a matrix of proteins located next to the inner nuclear membrane. The lamina family of proteins makes up the matrix and that is highly conserved in evolution. The family of lamina associated polypeptides (LAP) has several members with similar functions. Studies with fibroblast cells have revealed that fibroblast to pre-adipocyte transformation is strongly connected to LAP2a, the member of the LAP2a protein family (Dorner et al. 2006). While most splice variants associate with the nuclear envelope, LAP2a is involved in several nucleoplasmic activities including cell-cycle control and differentiation (Berger et al. 1996; Hutchison et al. 2001). LAP2a is synthesized in the 
cytoplasm and is then transported into the nucleus by a PKC-dependent mechanism (Dreger et al. 1999). The mere over-expression of LAP2a in fibroblasts is known to directly upregulate PPARY expression, an acknowledged marker and key transcription factor of preadipocyte differentiation (Dorner et al. 2006). In pre-adipocytes PPARY expression is followed by an increase of ADRP expression (adipose differentiation-related protein) a known direct target gene of PPARY. Although LAP2a over-expression alone initiates preadipocyte differentiation in fibroblasts, it is not sufficient to complete the adipocyte differentiation programme in the absence of additional stimuli (Dorner et al. 2006).

\subsection{Wnt signalling}

\subsubsection{Wnt signalling}

The Wnt family of 19 secreted glycoproteins controls a variety of developmental processes including cell fate specification, cell proliferation, cell polarity and cell migration. There are two main signalling pathways involved in the signal transduction process from the Wnt receptor (Frizzled) complex: the canonical or $\beta$-catenin dependent, and the non-canonical pathway, which splits into the polar cell polarity (PCP) or c-Jun-N-Terminal Kinase (JNK) / Activating Protein (AP1) dependent and the $\mathrm{Ca}^{2+}$ or Protein kinase C (PKC) / Calmodulin Kinase (CaMKII) / Nuclear Factor of Activating T-cells (NFAT) dependent signalling pathways.

Based on their ability to activate a particular Wnt pathway, Wnt molecules have been grouped as canonical (Wnt1, Wnt3, Wnt3a, Wnt7a, Wnt7b, Wnt8) (Torres et al. 1996) and non-canonical pathway activators (Wnt5a, Wnt4, Wnt11) (Torres et al. 1996), although promiscuity is a feature of both ligands and receptors.

\subsubsection{Canonical Wnt-pathway}

The canonical or $\beta$-catenin / Tcf dependent Wnt pathway is extensively investigated, and has been shown to be present in the thymus both in developing thymocytes (Ioannidis et al. 2001; Staal 2001; Xu et al. 2003) as well as in the thymic epithelium (Balciunate et al. 2001, Pongracz et al. 2003). Generally, in the absence of canonical Wnt-s, glycogen synthase

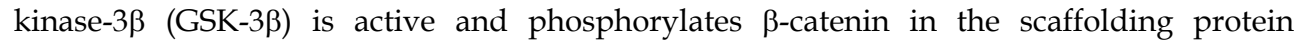
complex of adenomatous polyposis coli (APC) and axin (Ikeda 1998; Yamamoto 1999). The phosporylated $\beta$-catenin is targeted for ubiquitination and $26 \mathrm{~S}$ proteasome-mediated degradation, thereby decreasing the cytosolic level of $\beta$-catenin (Aberle 1997; Akiyama 2000). In the presence of Wnt-s, signals from the Wnt-Fz-LRP6 complex lead to the phosphorylation of three domains of Dishevelled (Dvl), a family of cytosolic signal transducer molecules (Noordermeer 1994). Activation of Dvl ultimately leads to phosphorylation and consequent inhibition of GSK-3 $\beta$. Inhibition of GSK-3 $\beta$ results in stabilisation and finally cytosolic accumulation of $\beta$-catenin, which then translocates to the nucleus where is required to form active transcription complexes with members of the TCell Factor (LEF1, TCF1, TCF3, TCF4) transcription factor family (Staal et al. 2003) and transcription initiator p300 (Labalette et al. 2004). Successful assembly of the transcription complex leads to the activation of various target genes including cyclin-D1 (Shtutman et al. 1999; Tetsu et al. 1999), c-myc (He et al. 1998), c-jun (Mann et al. 1999), Fra-1 (Mann et al. 1999), VEGFR (Zhang et al. 2001). 


\subsubsection{Non-canonical Wnt-pathways}

Generally, the two non-canonical signalling pathways are considered as regulators of canonical Wnt signalling and gene transcription. The two non-canonical Wnt pathways, the JNK/AP1 dependent, PCP (Yamanaka et al. 2002) and the PKC/CAMKII/NFAT dependent $\mathrm{Ca}^{2+}$ pathway (Wang et al. 2003), become activated following the formation of Wnt-Fz-LRP6 complex just like the canonical Wnt pathway. Although the non-canonical pathways differ from the canonical pathway in their dependency on the type of G-proteins (Malbon et al. 2001), activation of Dvl, downstream of Frizzled, is critical for further signal transduction in both (Boutros et al. 1998; Sheldahl et al. 2003). In further contrast to canonical Wnt signalling, phosphorylation of all three domains of Dvl, is not a requirement for transduction of non-canonical Wnt signals (Wharton Jr. 2001). Downstream of the cytosolic Dvl, the two non-canonical pathways activate different signalling cascades, which involve JNK or PKC and CaMKII, and trigger the transcription of different target genes. It has been proposed for non-canonical Wnt-signalling receptors to be linked directly to heterotrimeric G-proteins that activate phospholipase-C (PLC) isoforms, which in turn stimulate inositol lipid (i.e. $\mathrm{Ca}^{++} / \mathrm{PKC}$ ) signalling. Growing evidence, however, indicates that G-proteins are functionally diverse and that many of their cellular actions are independent of inositol lipid signalling (Peavy et al. 2005), indicating high levels of complexity in both the PKC dependent and independent Wnt signalling cascades. The JNK dependent PCP pathway, partly shares target genes with the canonical pathway, including cyclin-D1 (Schwabe et al. 2003) and matrix metalloproteinases (Nateri et al. 2005). Certainly, canonical Wnt signals can be rechanneled into the JNK pathway through naturally occurring, intracellular molecular switches, like the Dvl inhibitors, Naked-s (Nkd-1, Nkd-2) (Yan et al. 2001) leading to AP1 rather than TCF activation. AP1 is not a single protein, but a complex of various smaller proteins (cJun, JunB, JunD, cFos, FosB, Fra1, Fra2, ATF2, and CREB), which can form homoand heterodimers. The composition of the AP1 complex is a decisive factor in the activation of target genes, therefore the regulation of AP1 composition is important. Two prominent members of the AP1 complex cJun and Fra1 are both targets of the canonical Wnt pathway (Mann et al. 1999), indicating strong cross-regulation between the canonical and the noncanonical JNK dependent Wnt signalling cascades (Nateri et al. 2005).

While there are shared ligands (Rosso et al. 2005; Wang et al. 2005) and target genes (Shtutman et al. 1999; Schwabe et al. 2003) in the canonical and JNK dependent Wnt pathways, $\mathrm{Ca}^{2+} / \mathrm{PKC}$ dependent non-canonical signalling appears to be more independent of the other two pathways although cross-talk with both the $\beta$-catenin and the JNK pathways have been proposed (Kuhl et al. 2001). Generally, $\mathrm{Ca}^{2+}$ and $\mathrm{PKC}$-dependent signals are frequently linked to AP1, NFkB and NFAT activation.

\subsubsection{Inhibitory Wnt pathway}

Besides the canonical and non-canonical Wnt pathways, inhibitory Fz pathways have also been described. Fz1 and Fz6 are, for example, able to transmit inhibitory Wnt signals. While Fz1 inhibits Wnt signal transduction via a G-protein dependent manner (Roman-Roman et al. 2004) (Zilberberg et al. 2004), Fz6 (Golan et al. 2004) inhibits Wnt dependent gene transcription by activating the transforming growth factor $\beta$-activated kinase 1 (TAK1), a member of the MAPKKK family, and nemo-like kinase (NLK) (Ishitani et al. 2003; Smit et al. 2004) via a $\mathrm{Ca}^{++}$dependent signalling cascade. NLK phosphorylates TCF that consequently 
cannot bind to $\beta$-catenin, and the formation of active transcription complex becomes inhibited (Smit et al. 2004) .

\subsubsection{Wnt-s in ageing}

As Wnt-s are important regulators of stem cell survival and differentiation, recent studies have started to investigate the role of Wnt family members in ageing. Most studies confirmed that drastically reduced Wnt levels can trigger ageing as tissue specific stem cells fail to replenish mesenchymal tissues as a result of low Wnt signals. In contrast, the KLOTHO mouse, that carries a single gene mutation in KLOTHO, an endogenous Wnt antagonist also shows signs of accelerated ageing (Liu et al. 2007). It has been proposed that increased Wnt signalling leads to continuous stem cell proliferation which finally results in depletion of the stem cell pool (Brack et al. 2007).

\subsubsection{Wnt-s in the thymus}

The main source of Wnt glycoproteins in the thymus is the thymic epithelium, where 14 members of the Wnt family together with all 10 known Wnt receptors of the seven-loop transmembrane receptor family, Frizzleds (Fz) have been identified (Pongracz et al. 2003). That is a striking difference compared with thymocytes where developmentally regulated receptor expression is limited to Fz-5 and Fz-6 (Pongracz et al. 2003). The assembly of an active Wnt-Fz receptor complex also requires the presence of a co-receptor, the low density lipoprotein related protein 5 and 6 (LRP5/6) (Pinson 2000; Tamai 2000; Wehrli 2000), which is expressed both in thymocytes and thymic epithelial cells, indicating full ability in both cell types to respond to Wnt signals.

Initial experiments, by manipulating the level of some Wnt-s and soluble Fz-s, have shown perturbation of T-cell development (Staal 2001; Mulroy 2002), highlighting the importance of Wnt dependent signalling for T-cell proliferation and differentiation. Recent data (Pongracz et al. 2003) revealed differential expression of Wnt ligands and receptors in thymic cell types raising that T-cell development may be influenced by indirect events triggered by Wnt signalling within the thymic epithelium.

The canonical pathway has been shown to have an important role in thymocyte development regulating survival and differentiation (Ioannidis et al. 2001; Staal 2001; Pongracz et al. 2003; Xu et al. 2003). In a thymic epithelial cell study, transgenic expression of cyclin-D1, one of the principal target genes of Wnt signalling, has lead to the expansion of the entire epithelial compartment (Klug et al. 2000) suggesting that canonical Wnt signalling is involved in thymic epithelial cell proliferation, strengthening the argument, that thymic epithelial development is regulated by Wnt-s. So far, signalling studies have revealed, that Wnt4 can activate both the canonical (Lyons et al. 2004) and the non-canonical (Torres et al. 1996) (Chang et al. 2007; Kim et al. 2009) Wnt-pathways.

\subsection{Steroids and ageing}

Physiological steroids are implicated in the regulation of thymic ageing. For example both surgical and chemical castration have been demonstrated to decrease the progression of thymic ageing (Qiao et al. 2008) indicating that high steroid levels would accelerate the 
ageing process of the thymus. Still, steroids used in therapy have not been fully investigated for their effects on immune senescence. Autoimmune diseases and haematological malignancies are often treated by steroids, as they effectively promote apoptosis of leukaemia cells and trigger complex anti-inflammatory actions (Stahn et al. 2007). Apart from triggering decreased expression of cytokines and MHC class II (MHC II) molecules, glucocorticoid (GC) analogues like dexamethasone (DX) also induce apoptotic death of peripheral (Wust et al. 2008) and developing T-cells. In mouse models, GCs cause massive thymocyte depletion, especially in the $\mathrm{CD} 4{ }^{+} \mathrm{CD} 8^{+}(\mathrm{DP})$ thymocyte population, (Wiegers et al. 2001; Berki et al. 2002; Jondal et al. 2004) blocking de novo T-cell production. Experiments have also demonstrated that high-dose GCs induce a dramatic (Blomgren et al. 1970) and apoptosis-associated (Boersma et al. 1979) involution of the thymus, and not only thymocytes but also TECs are seriously affected (Dardenne et al. 1986). Recent reports (Fletcher et al. 2009) have highlighted that TEC depletion appears reversible, and thymic epithelial stem cells play an important role in this process.

\section{Thymic senescence - Current opinion}

\subsection{Physiological thymic senescence}

\subsubsection{Disintegration of epithelial network, adipose involution}

Senescence exhibits characteristic histological changes in both the human and mouse thymus (Oksanen 1971; Marinova 2005). In young adult mice (at 1 month of age), histology reveals strict segregation of epithelial cell compartments by staining for medullary $\left(\right.$ EpCAM1 ${ }^{++}$, Ly51-) and cortical (EpCAM1 ${ }^{+}$, Ly51 ${ }^{++}$) epithelial cellular subsets (Kvell et al. 2010). Thymic morphology shows high level of integrity just preceding puberty/early adulthood. However, the highly organized structure disintegrates and becomes chaotic by the age of 1 year. By this age the strict cortico-medullary delineation becomes disintegrated, degenerative vacuoles appear surrounded by areas showing strong co-staining with both epithelial markers. Also significant cellular areas appear that lack staining with either epithelial markers, a pattern completely absent at the young adult age. Staining for extracellular matrix components of fibroblast origin $\left(E R-T R 7^{++}\right)$identifies mesenchymal elements. The staining pattern with ER-TR7 and EpCAM1 is strikingly different at the two ages examined. In young adult thymic tissue sections, a-EpCAM1 and a-ER-TR7- show little tendency for co-localization. In stark contrast, already by the age of 9 months a-EpCAM1 and ER-TR7-staining show significant overlap within the thymic medulla. The disorganization of thymic epithelial network is followed by the emergence of adipocytes. If thymic sections of senescent mice are co-stained with neutral lipid deposit-specific stains then histology shows the presence of relatively large, inflated cells in which the cytoplasm is pushed to the periphery by red-staining neutral lipid deposits, a pattern characteristic of adipose cells (Kvell et al. 2010).

\subsubsection{Gene expression changes in the thymic epithelium during ageing}

To investigate the underlying molecular events of thymic epithelial senescence, the gene expression changes may be investigated in TECs purified from 1 month and 1 year old mice (Kvell et al. 2010). The expression of both Wnt4 and FoxN1 decreases in thymic epithelial cells. Highly decreased level (or total absence in some cases) of FoxN1 could be the 
consequence of strong Wnt 4 down-regulation by the age of 1 year, indicating that TECs can down-regulate FoxN1 expression while maintaining that of epithelial cell surface markers like EpCAM1 (Balciunaite et al. 2002). At the same time, mRNA levels of pre-adipocyte differentiation markers PPAR $\gamma$ and ADRP rise with age. This finding is in harmony with histological data demonstrating the emergence of adipocytes in the thymic lobes of senescent mice. The expression of lamin1, a key component of the nuclear lamina remains unaffected during senescence in thymic epithelial cells; whereas, the expression of LAP2a increases significantly. This degree of dissociation between lamin1 and LAP2a expression is of note and suggests functional differences despite conventionally anticipated association of lamin1 and LAP2 molecular family members. LAP2a up-regulation associated with agerelated adipose involution is, however, in perfect agreement with other literature data suggesting the pre-adipocyte differentiation-promoting effect of LAP2a in fibroblasts (Dorner et al. 2006) and the same is suggested by our reports performed, however, with epithelial cells (Kvell et al. 2010).

According to literature, EMT is associated with differential expression of E- (decrease) and $\mathrm{N}$-cadherin (increase) (Seike et al. 2009). TECs were tested for these markers to investigate whether the first step towards pre-adipocyte differentiation is the EMT of epithelial cells. In purified TECs while E-cadherin mRNA levels significantly decreased, N-cadherin gene expression showed a slight increase during ageing, indicating that EMT might be the initial step in epithelial cell transition and trans-differentiation.

\subsubsection{Studies of LAP2 $\alpha$ and Wnt4 effects on TEC}

The hypothesis that both LAP2a and Wnt4 play important though opposite roles in thymic senescence may be addressed using LAP2a over-expressing or Wnt4-secreting transgenic TEP1 (mouse primary-derived thymic epithelial) cell lines. The use of a primary-derived model cell line provides the advantage of absolute purity, the complete lack of other cell types that could potentially affect the gene expression profile of epithelial cells (Beardsley et al. 1983). Using such cells quantitative RT-PCR analysis revealed that LAP2a overexpression triggers an immense surge of PPARY expression. Such an increase in mRNA level suggests that this is not a plain quantitative, but rather a qualitative change. ADRP a direct target gene of PPARY also becomes up-regulated although to a lesser extent. On the other hand in Wnt4-secreting cells the mRNA level of both PPARY and ADRP decreased (Kvell et al. 2010).

\subsubsection{Fz-4 and Fz-6 expression and distribution are affected by age}

Once the preventive role of Wnt 4 was established in adipocyte-type trans-differentiation of TECs, receptor associated signalling studies have ensued to investigate what signal modifications can lead to Wnt4 effects. Initially, expression levels of the Wnt 4 receptors, Fz4 and Fz-6 were analysed in thymi of young adult and mature adult ( 1 month and 9 months old) mice (Varecza et al. 2011). Q-RT-PCR analysis of TECs showed increased expression of both Fz-4 and Fz-6 mRNA with age. Immune-histochemistry using Fz-4 and Fz-6 specific antibodies confirmed elevated levels of both receptor proteins. Additionally, differential expression pattern of Fz-4 and Fz-6 was also observed in the thymic medulla and cortex. While in the young thymus the medulla (EpCAM1++ $/$ Ly51-) was preferentially stained for 
Fz4 and Fz6, the cortex $\left(E \mathrm{EPAM} 1^{+} / \mathrm{Ly} 51^{+}\right)$only faintly stained for these receptors. In contrast to the young tissue, the 9 month old thymus shows a different pattern as the whole section including the cortex has become increasingly positive for both receptors (Varecza et al. 2011).

\subsection{5 $\mathrm{PKC} \delta$ translocation and its relation with Wnt4 signalling}

Since Wnt4 levels as well as its receptors are modulated during the ageing process, further studies were performed to investigate active receptor signalling that is invariably associated with modified level of phosphorylation of receptor associated signalling molecules. Since Fz-s associate with Dvls that are phosphorylated by the $\delta$ isoform of PKCs, PKC $\delta$ activity was in focus. To test the involvement of PKC $\delta$ in Wnt4 signal transduction, increased Wnt4 levels were achieved using the supernatant of Wnt4-transgenic cell line (Varecza et al. 2011). Wild type TEP1 cells were exposed to SNs of control and Wnt4-secreting cells for 1 hour, then cytosolic and membrane fractions were isolated from cell lysates. Similar to previous studies with Wnt-5a (Giorgione et al. 2003), Western blot analysis revealed that within one hour of Wnt 4 exposure PKC $\delta$ translocated into the membrane fraction where the cleavage products (Kanthasamy et al, 2006) characteristic of PKC $\delta$ activation were detectable. Additionally, increased membrane localisation of PKC $\delta$ was also detected in the Wnt4overexpressing cell line. As both Fz-4 and Fz-6 levels increased with age, it was assumed that active receptor signalling might require more PKC $\delta$ during ageing. Indeed, apart from localisation of PKC $\delta$ to the membrane fraction, up-regulation of PKC $\delta$ was also detected in the ageing thymi. To investigate the role of PKC $\delta$ involvement in Wnt4 signalling, PKC $\delta$ activity level was modified by either over-expressing wild type PKC $\delta$ or by silencing PKC $\delta$ translation using siRNA technology. CTGF was used as a read-out gene based on data of previous experiments (Varecza et al. 2011). Surprisingly, although over-expression of PKC $\delta$ had no radical effect on Wnt4 target gene transcription, even moderate down-regulation of PKC $\delta$ was able to significantly increase CTGF expression in the presence of Wnt4, indicating that PKC $\delta$ might be involved in a negative regulatory loop.

\subsubsection{Negative regulatory loops of signalling during senescence}

As Fz-6 has been implicated in previous studies as a negative regulator of $\beta$-catenin dependent signalling, it was important to determine whether PKC $\delta$ is preferentially associated with either Wnt4 receptors. Experiments demonstrated age dependent increase of both Fz-6 and PKC $\delta$ as well as co-localisation of Fz-6 and PKC $\delta$ (Varecza et al. 2011). While in the young thymus Fz-6 and PKC $\delta$ co-localisation is more pronounced in the thymic cortex, in the ageing thymus it is the medulla that exhibits stronger staining for both proteins. While increased expression and activity of the Fz-6 receptor, a suppressor of the canonical Wnt signalling pathway explains some aspects of uneven target gene transcription following manipulation of PKC $\delta$ activity, parallel changes like up-regulation of $\mathrm{Fz}-4$ also occur during ageing that might add to the complexity of the signalling process. Increase in $\mathrm{Fz}-4$ levels in ageing mice correlated with increased CTGF gene expression.

If Fz-6 that also increases during senescence is truly a suppressor of $\beta$-catenin signalling then CTGF expression should have decreased or remained unchanged as Fz-4 transmitted signals would have been quenched by Fz-6 signalling. To test the above hypothesis, we have 
considered the following: CTGF has recently been reported to negatively regulate canonical Wnt signalling by blocking $\beta$-catenin stabilisation via GSK3 $\beta$ activation leading to phosphorylation and consequent degradation of $\beta$-catenin (Luo et al. 2004), indicating that CTGF might be part of a negative feed-back loop. The expression of Fz-8 (Mercurio et al. 2004) a recently reported receptor for CTGF increased in ageing mice, while FoxN1 the direct target of $\beta$-catenin dependent Wnt4 signalling (Balciunaite et al. 2002) became undetectable (Kvell et al. 2010).

\subsection{Thymic senescence model}

\subsubsection{Steroid induced accelerated thymic senescence}

A commonly held view is that the thymus involutes at puberty, and this model is based primarily on studies showing that growth hormone (GH) and sex steroids can affect cell production in the thymus and that their concentrations decrease with age (Min et al. 2006). As steroids are frequently applied medications, investigations were extended to identify similarities in induced and physiological senescence and potential mechanisms that might be able to reduce adipose involution of the thymus.

Similar to physiological senescence, the level of FoxN1 transcription factor and its regulator Wnt4 decreased in TECs within 24 hours following a single dose DX injection and remained low for over 1 week (Talaber et al. 2011).

However, in clinical treatments GC analogues are widely used for extended periods of time, rather than single shots. To mimic this pattern of clinical application, mice were injected with DX repeatedly for a time course of 1 month. Both Wnt4 and FoxN1 levels were measured drastically down-regulated, while the adipocyte differentiation factor ADRP, down-stream target of PPARY was significantly increased. The results indicate that adipocyte-type trans-differentiation is completed at the molecular level over a much shorter time period following exogenous steroid-induced senescence compared to physiological rate senescence (Talaber et al. 2011).

\subsubsection{Wnt4 inhibits steroid-induced adipose trans-differentiation}

To test whether Wnt4 can prevent adipocyte type trans-differentiation, Wnt4 overexpressing TEP1 cell line was exposed to DX for a week. While in the control cell line DX exposure induced up-regulation of adipose trans-differentiation markers, within the Wnt4 over-expressing cell line, none of the adipose trans-differentiation markers were upregulated indicating that Wnt4 alone can efficiently protect TECs against exogenous steroidinduced adipose trans-differentiation (Talaber et al. 2011).

\section{Conclusions}

\subsection{Physiological thymic epithelial senescence}

There are characteristic changes in the gene expression profile of purified thymic epithelial cells during thymic epithelial senescence (Kvell et al. 2010). Of note, Wnt4 level decreases, while LAP $2 \alpha$ level increases. Also, the expression of the transcription factor FoxN1 required for maintaining thymic epithelial identity diminishes with age. On the other hand, adipose 
differentiation is confirmed at the molecular level by the increased expression of PPAR $\gamma$ and ADRP. This process is accompanied by shift from E-cadherin to N-cadherin, typical for EMT (epithelial to mesenchymal transition). These pioneer experiments confirm in both a model cell line and purified primary cells rendered transgenic for either Wnt4 or LAP2 $\alpha$ that their opposing effects antagonistically influence adipose trans-differentiation of thymic epithelial cells via EMT. This has lead to the establishment of a novel, confirmed theory for the source of adipose cells replacing functional thymic epithelial network during senescence (see Figure 1). Apparently, these cells do not differentiate from invading or resident mesenchymal cells, but rather trans-differentiate (via EMT) from thymic epithelial cells (Kvell et al. 2010).

\section{Thymic epithelial identity}
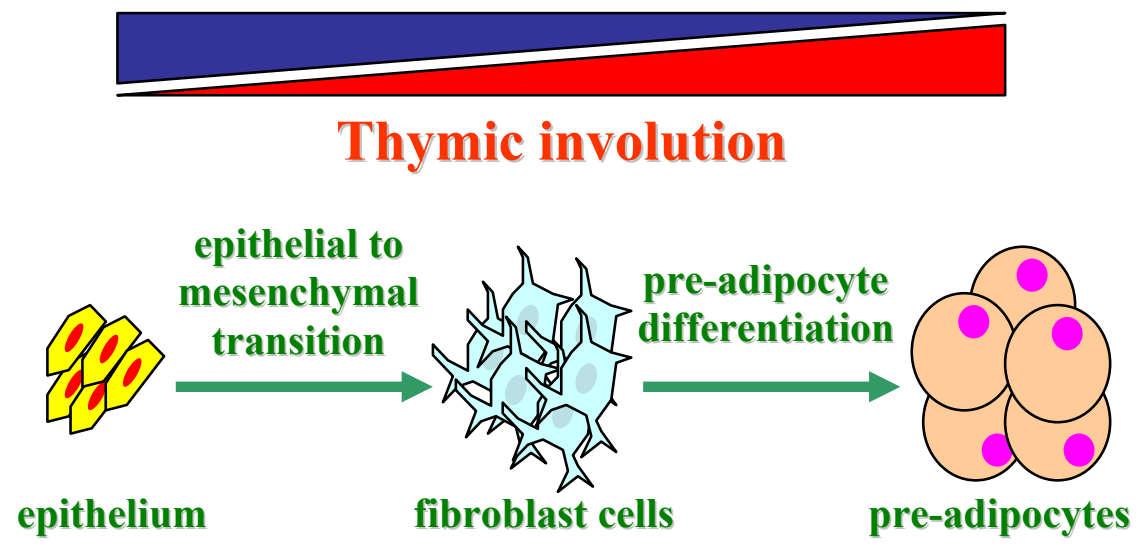

Fig. 1. Model of thymic involution process

Dedifferentiation of thymic epithelial cells triggers EMT (epithelial to mesenchymal transition) first, and then the resulting fibroblast cells undergo the conventional route of differentiation program towards adipocyte-lineage.

\subsection{Signal transduction mechanisms involved in thymic epithelial senescence}

While individual molecules, such as Wnt4 or LAP2 $\alpha$ can serve as therapeutic targets to modify the ageing process, identification of complex interactions amongst signalling networks can provide further details. Investigation of Wnt signal transduction in the thymic epithelium has revealed that signalling pathways are activated or inhibited in an orderly fashion (Varecza et al. 2011). Initially, both Wnt4 receptors, Fz-4 and Fz-6 are up-regulated at young adult age. However, signals from Fz-4 and Fz-6 are different. While signals from Fz-4 initiate $\beta$-catenin dependent gene transcription, Fz-6 signals lead to suppression of $\beta$ catenin dependent signalling via increased activities of TGF $\beta$-Activated Kinase (TAK) and Nemo-Like-Kinase (NLK). Fz-associated signals also require PKC $\delta$ to transmit Wnt signals. PKC $\delta$ associates with Fz- 6 aiding suppression of $\beta$-catenin dependent signalling. Additional to Fz-6 signalling, connective tissue growth factor (CTGF, a $\beta$-catenin target gene) can also 
feedback on $\beta$-catenin dependent signal transduction. CTGF can interact with Fz-8 as well as LRP6, an important co-receptor of Wnt signalling and can trigger activation of GSK3 $\beta$. This latter leads to accelerated proteasomal degradation of $\beta$-catenin and hence suppression of Wnt signals. Multiple signalling mechanisms that lead to suppression of Wnt signalling is summarized in Figure 2 (Varecza et al. 2011).

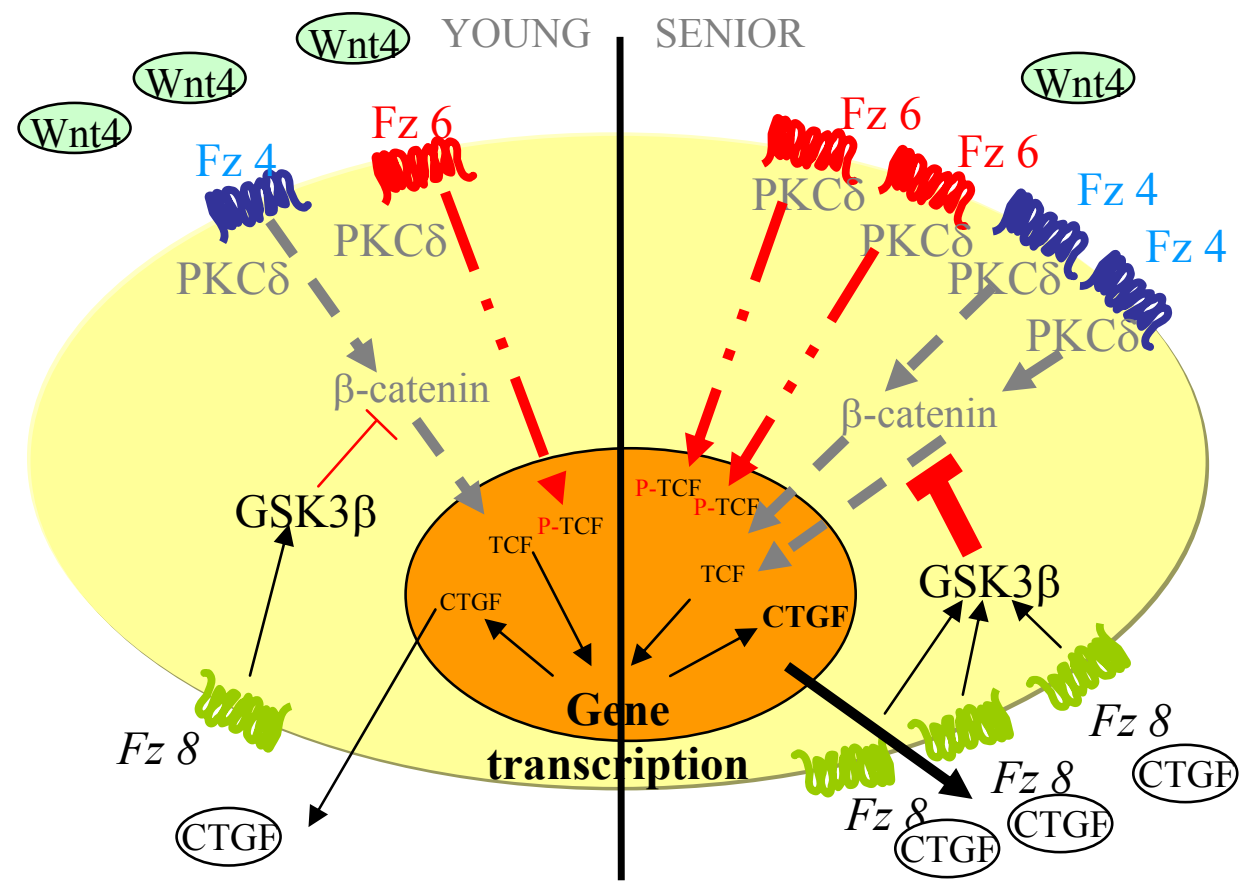

Fig. 2. Model of molecular mechanisms in thymic aging

At young age, Wnt4 levels are high and Wnt4 molecules compete for a moderate number of Fz receptors. While Fz-4 activates canonical Wnt signalling, signals from Fz-6 inhibit $\beta$-catenin dependent gene transcription keeping Wnt 4 dependent signalling in balance. During the ageing process, Wnt 4 levels decrease, while receptor expression increases with proportionally higher Fz- 6 . The $\beta$-catenin dependent Fz-4 signals lead to increased expression of CTGF. The CTGF receptor Fz8 is also up-regulated leading to enhanced activation of GSK3 $\beta$. All these signalling events lead to loss of thymic epithelial cell characteristics and provide an opening for molecular events leading up to adipocyte type trans-differentiation.

\subsection{Accelerated-rate, induced model of thymic epithelial senescence}

Glucocorticoids are immunosuppressive drugs often used for treatment of autoimmune diseases and haematological malignancies. Although glucocorticoids can induce apoptotic cell death directly in developing thymocytes, how exogenous glucocorticoids affect the 
thymic epithelial network that provides the microenvironment for $\mathrm{T}$ cell development has been poorly characterised. The effect of DX (dexamethasone) on thymic epithelial cells has been tested both in vitro (model cell line) and in vivo (mouse model) (Talaber et al. 2011). In vivo, following single treatment with pharmacologically relevant dose of DX reversible changes in gene expression profile identical to physiological thymic epithelial senescence have been recorded, but occurring at a highly accelerated pace (see Figure 1). Specifically, the expression of Wnt4 and FoxN1 decreased, while LAP2 $\alpha$ and PPAR $\gamma$ levels increased. Moreover, sustained DX treatment has induced the elevation of ADRP expression as well. The same changes of gene expression profile have been observed using the model TEP1 (thymic epithelial) cell line, however, in vitro studies have shown the molecular level rescue of thymic epithelial cells from adipose trans-differentiation due to the over-expression of Wnt4. These studies reveal the currently neglected effect of steroid therapy on thymic epithelial cells in patients receiving sustained or even single dose treatment and highlights novel potential side-effects appearing in the form of accelerated thymic senescence (Talaber et al. 2011).

\section{Perspectives}

\subsection{Intervention possibilities of thymic rejuvenation}

This chapter summarised current knowledge on thymic senescence, a central immune tissue that suffers significant morphological changes and functional impairment during ageing. The epithelial network is in focus that provides the niche for developing thymocytes until adipose involution begins. We have discussed physiological thymic epithelial senescence in detail with respect to the signalling pathways involved in the process (Kvell et al. 2010). It has also been shown that steroid induced accelerated rate thymic epithelial senescence quite resembles physiological rate senescence (except for its speed) at the molecular level (Talaber et al. 2011). The data presented confirm that Wnt 4 can efficiently rescue thymic epithelial cells from steroid-induced adipose involution at the molecular level (Talaber et al. 2011). Since physiological and steroid-induced thymic epithelial senescence are identical at the molecular level, it is anticipated that sustained Wnt4 presence in the thymic context can efficiently prolong FoxN1 expression, maintain thymic epithelial identity and prevent transdifferentiation towards adipocyte lineage. The same works identify LAP2 $\alpha$ as a pro-ageing molecular factor promoting the trans-differentiation of thymic epithelial cells into preadipocytes via EMT. The thymus selective decrease of LAP2 $\alpha$ activity through small molecule compounds could theoretically shift the delicate molecular balance towards the same direction as increased Wnt4 presence.

However, there are also other methods that can efficiently support major functions of the thymus: T cell maturation and selection. An example is the thymus-specific enrichment of transgenic IL7 proteins using IL7-CCR9 fusion proteins that selectively home and accumulate in the thymic context to reinforce thymocyte development and maturation (Henson et al. 2005). This method has been characterised in detail and is currently being geared up towards potential human application in the form of inhalation products selectively delivering IL7 to the thymus (Aspinall et al. 2008).

The thymus-specific ablation of sex steroids also offers a target point for such interventions. Major involution in thymus mass occurs in parallel with the advance of puberty and 
correlation has been drawn with sex steroid levels. The use of thymus selective 11ß-HSD1 inhibitor compounds could also theoretically decrease thymocyte sensitivity to steroidinduced apoptosis and steroid-induced epithelial molecular senescence, providing synergistic mechanism of action. Such artificial compounds (like the PF-00915275) have already been tested in healthy volunteers and were approved for safety (Courtney et al. 2008). However, these compounds do not specifically accumulate in the thymus and have not been tested in the thymic context.

Alternative methods for thymic rejuvenation include those targeting KGF, ghrelin and GH signal transduction pathways (Aspinall et al 2008). The ideal future thymus rejuvenation system that works selectively in the thymus at high efficiency and low side-effect ratio would likely constitute a combination of the above outlined methods and would efficiently aid restoration of immune competence.

\subsection{Social and economic impact}

By targeting and specifically inhibiting the molecular pathways that drive thymic adipose involution / immune senescence, it is possible to extend immune health-span within lifespan, and improve health and quality of life, and also significantly decrease healthcare costs. This effect is expected to be very significant as - opposed to certain diseases - the physiological process of immune senescence affects all individuals, including currently healthy people.

It is to be evaluated whether an immune-fitness extending treatment would be predominantly useful as preventive treatment applied in younger individuals or would rather be useful as a reversal treatment in elderly individuals with various stages of thymic adipose degeneration. Both scenarios would affect vast segments of the population and would yield similarly significant economic and social benefit.

\section{Acknowledgement}

The authors are grateful to Prof. S. Amos (Institute of Haematology, Chaim Sheba Medical Centre, Tel-Hashomer, Israel) for providing the wild type murine LAP2 $\alpha$ construct.

Experimental work performed by authors was funded by the following grants: OTKA PD 78310 to KK, Wellcome Trust 079415 and SROP-4.2.2/08/1/2008-0011 to JEP.

\section{References}

Aberle, H., Bauer, A., Stappert, J., Kispert, A., and Kemler, R. (1997). "b-Catenin is a target for the ubiquitin-proteosome pathway." EMBO J. 16: 3797-3804.

Akiyama, T. (2000). "Wnt/b-catenin signaling." Cytokine\&Growth Factor Rev. 11: 273-282.

Alves NL, Richard-Le Goff O, Huntington ND, Sousa AP, Ribeiro VS, Bordack A, Vives FL, Peduto L, Chidgey A, Cumano A, Boyd R, Eberl G, Di Santo JP. (2009). "Characterization of the thymic IL-7 niche in vivo." Proc Natl Acad Sci U S A 106(5): 1512-7. 
Anderson G, Owen JJ, Moore NC, Jenkinson EJ. "Thymic epithelial cells provide unique signals for positive selection of $\mathrm{CD} 4{ }^{+} \mathrm{CD} 8+$ thymocytes in vitro." J. Exp. Med. 179: 2027-2031.

Aspinall R, Mitchell W. Reversal of age-associated thymic atrophy: treatments, delivery, and side effects. Exp Gerontol. 2008 Jul;43(7):700-5.

Aydar Y, Balogh P, Tew JG, Szakal AK. Follicular dendritic cells in aging, a "bottle-neck" in the humoral immune response. Ageing Res Rev. 2004 Jan;3(1):15-29.

Balciunaite G, Keller MP, Balciunaite E, Piali L, Zuklys S, Mathieu YD, Gill J, Boyd R, Sussman DJ, Holländer GA. (2002). "Wnt glycoproteins regulate the expression of FoxN1, the gene defective in nude mice." Nat. Immunol. 3(11): 1102-1108.

Beardsley TR, Pierschbacher M, Wetzel GD, Hays EF. (1983). "Induction of T-Cell Maturation by a Cloned Line of Thymic Epithelium (TEPI) 10.1073/pnas.80.19.6005." Proceedings of the National Academy of Sciences 80(19): 6005-6009.

Bennett AR, Farley A, Blair NF, Gordon J, Sharp L, Blackburn CC. (2002). "Identification and characterization of thymic epithelial progenitor cells." Immunity 16(6): 803-814.

Berger R, Theodor L, Shoham J, Gokkel E, Brok-Simoni F, Avraham KB, Copeland NG, Jenkins NA, Rechavi G, Simon AJ. (1996). "The characterization and localization of the mouse thymopoietin/lamina-associated polypeptide 2 gene and its alternatively spliced products." Genome Res 6(5): 361-70.

Berki T, Pálinkás L, Boldizsár F, Németh P. (2002). "Glucocorticoid (GC) sensitivity and GC receptor expression differ in thymocyte subpopulations." Int Immunol 14(5): 463-9.

Blackburn, C. and N. Manley (2004). "Developing a new paradigm for thymus organogenesis." Nat Rev Immunol 4(4): 278-289.

Bleul, C. and T. Boehm (2000). "Chemokines define distinct microenvironments in the developing thymus." Eur. J. Immunol. 30: 3371-3379.

Bleul, C. and T. Boehm (2005). "BMP signaling is required for normal thymus development." J Immunol 175: 5213-5221.

Blomgren, H. and B. Andersson (1970). "Characteristics of the immunocompetent cells in the mouse thymus: cell population changes during cortisone-induced atrophy and subsequent regeneration." Cell Immunol 1(5): 545-60.

Boersma W, Betel I, van der Westen G. (1979). "Thymic regeneration after dexamethasone treatment as a model for subpopulation development." Eur J Immunol 9(1): 45-52.

Boutros M, Paricio N, Strutt DI, Mlodzik M. (1998). "Dishevelled activates JNK and discriminates between JNK pathways in planar polarity and wingless signaling." Cell 94: 109-118.

Brack AS, Conboy MJ, Roy S, Lee M, Kuo CJ, Keller C, Rando TA. (2007). "Increased Wnt Signaling During Aging Alters Muscle Stem Cell Fate and Increases Fibrosis." Science 317(5839): 807-810.

Chang J, Sonoyama W, Wang Z, Jin Q, Zhang C, Krebsbach PH, Giannobile W, Shi S, Wang CY. (2007). "Noncanonical Wnt-4 signaling enhances bone regeneration of mesenchymal stem cells in craniofacial defects through activation of p38 MAPK." Journal of Biological Chemistry 282(42): 30938-30948.

Chen L, Xiao S, Manley NR. (2009). "Foxn1 is required to maintain the postnatal thymic microenvironment in a dosage-sensitive manner." Blood 113(3): 567-574. 
Cheng L, Guo J, Sun L, Fu J, Barnes PF, Metzger D, Chambon P, Oshima RG, Amagai T, Su DM. (2010). "Postnatal Tissue-specific Disruption of Transcription Factor FoxN1 Triggers Acute Thymic Atrophy." Journal of Biological Chemistry 285(8): 5836-5847.

Chidgey A, Dudakov J, Seach N, Boyd R.(2007). "Impact of niche aging on thymic regeneration and immune reconstitution." Semin Immunol 19(5): 331-40.

Courtney R, Stewart PM, Toh M, Ndongo MN, Calle RA, Hirshberg B. Modulation of 11beta-hydroxysteroid dehydrogenase (11betaHSD) activity biomarkers and pharmacokinetics of PF-00915275, a selective 11betaHSD1 inhibitor. J Clin Endocrinol Metab. 2008 Feb;93(2):550-6.

Crisa L, Cirulli V, Ellisman MH, Ishii JK, Elices MJ, Salomon DR. (1996). "Cell adhesion and migration are regulated at distinct stages of thymic $\mathrm{T}$ cell development: the roles of fibronectin, VLA4, and VLA5." J Exp Med 184(1): 21-28.

Dardenne M, Itoh T, Homo-Delarche F. (1986). "Presence of glucocorticoid receptors in cultured thymic epithelial cells." Cell Immunol 100(1): 112-8.

de Grey AD. "The natural biogerontology portfolio: "defeating aging" as a multi-stage ultragrand challenge." Ann N Y Acad Sci. 2007 Apr;1100:409-23.

Derbinski J, Schulte A, Kyewski B, Klein L. (2001). "Promiscuous gene expression in medullary thymic epithelial cells mirrors the peripheral self." Nat. Immunol. 2(11): 1032-1039.

Dixit, V. D. (2010). "Thymic fatness and approaches to enhance thymopoietic fitness in aging." Curr Opin Immunol 22(4): 521-8.

Dooley J, Erickson M, Roelink H, Farr AG. (2005). "Nude thymic rudiment lacking functional foxn1 resembles respiratory epithelium." Dev Dyn. 233(4): 1605-1612.

Dorner D, Vlcek S, Foeger N, Gajewski A, Makolm C, Gotzmann J, Hutchison CJ, Foisner R. (2006). "Lamina-associated polypeptide 2alpha regulates cell cycle progression and differentiation via the retinoblastoma-E2F pathway." J Cell Biol 173(1): 83-93.

Dreger M, Otto H, Neubauer G, Mann M, Hucho F. (1999). "Identification of phosphorylation sites in native lamina-associated polypeptide 2 beta." Biochemistry 38(29): 9426-34.

Farr, A. and A. Rudensky (1998). "Medullary thymic epithelium: a mosaic of epithelial "self"?" J. Exp. Med. 188(1): 1-4.

Fletcher AL, Lowen TE, Sakkal S, Reiseger JJ, Hammett MV, Seach N, Scott HS, Boyd RL, Chidgey AP. (2009). "Ablation and regeneration of tolerance-inducing medullary thymic epithelial cells after cyclosporine, cyclophosphamide, and dexamethasone treatment." J Immunol 183(2): 823-31.

Ge, Q. and W. Chen (2000). "Effect of murine thymic epithelial cell line (MTEC1) on the functional expression of CD4(+)CD8(-) thymocyte subgroups." Int. Immunol. 12(8): 1127-1133.

Gill J, Malin M, Holländer GA, Boyd R. (2002). "Generation of a complete thymic microenvironment by MTS24(+) thymic epithelial cells." Nat. Immunol. 3(7): 635642.

Giorgione J, Hysell M, Harvey DF, Newton AC. (2003). "Contribution of the C1A and C1B domains to the membrane interaction of protein kinase C." Biochemistry 42(38): 11194-11202. 
Golan T, Yaniv A, Bafico A, Liu G, Gazit A. (2004). "The human frizzled 6 (HFz6) acts as a negative regulator of the canonical Wnt b-catenin signaling cascade." J. Biol. Chem. 279(15): 14879-14888.

Grubeck-Loebenstein, B. (2009). "Fading Immune Protection in Old Age: Vaccination in the Elderly." J Comp Pathol.

Gui J, Zhu X, Dohkan J, Cheng L, Barnes PF, Su DM. (2007). "The aged thymus shows normal recruitment of lymphohematopoietic progenitors but has defects in thymic epithelial cells." Int Immunol 19(10): 1201-11.

He TC, Sparks AB, Rago C, Hermeking H, Zawel L, da Costa LT, Morin PJ, Vogelstein B, Kinzler KW. (1998). "Identification of c-MYC as a target of the APC pathway." Science 281(5382): 1509-1512.

He, X. and D. J. Kappes (2006). "CD4/CD8 lineage commitment: light at the end of the tunnel?" Curr Opin Immunol 18(2): 135-42.

Henson SM, Snelgrove R, Hussell T, Wells DJ, Aspinall R. An IL-7 fusion protein that shows increased thymopoietic ability. J Immunol. 2005 Sep 15;175(6):4112-8.

Hsu, H. C. and J. D. Mountz (2003). "Origin of late-onset autoimmune disease." Immunol Allergy Clin North Am 23(1): 65-82, vi.

Hutchison CJ, Alvarez-Reyes M, Vaughan OA. (2001). "Lamins in disease: why do ubiquitously expressed nuclear envelope proteins give rise to tissue-specific disease phenotypes?" J Cell Sci 114(Pt 1): 9-19.

Ikeda, S., Kishida, S., Yamamoto, H., Murai, H., Koyama, S., Kikuchi, A. (1998). "Axin, a negative regulator of the Wnt signaling pathway, forms a complex with GSK3b and b-catenin and promotes GSK-3b-dependent phosphorylation of b-catenin." The EMBO J. 17: 1371-1384.

Ioannidis V, Beermann F, Clevers H, Held W. (2001). "The b-catenin-TCF1 pathway ensures CD4+CD8+ thymocyte survival." Nature Immunology 2: 691-697.

Ishitani T, Kishida S, Hyodo-Miura J, Ueno N, Yasuda J, Waterman M, Shibuya H, Moon RT, Ninomiya-Tsuji J, Matsumoto K. (2003). "The TAK1-NLK Mitogen-activated protein kinase cascade functions in the Wnt-5a/Ca2+ pathway to antagonize Wnt/b-catenin signaling." Mol. Cell Biol. 23(1): 131-139.

Jin EJ, Park JH, Lee SY, Chun JS, Bang OS, Kang SS. (2006). "Wnt-5a is involved in TGFbeta3-stimulated chondrogenic differentiation of chick wing bud mesenchymal cells." Int J Biochem Cell Biol 38(2): 183-95.

Jondal M, Pazirandeh A, Okret S. (2004). "Different roles for glucocorticoids in thymocyte homeostasis?" Trends Immunol 25(11): 595-600.

Kanthasamy AG, Anantharam V, Zhang D, Latchoumycandane C, Jin H, Kaul S, Kanthasamy A. A novel peptide inhibitor targeted to caspase-3 cleavage site of a proapoptotic kinase protein kinase C delta (PKCdelta) protects against dopaminergic neuronal degeneration in Parkinson's disease models. Free Radic Biol Med. 2006 Nov 15;41(10):1578-89.

Kim YC, Clark RJ, Pelegri F, Alexander CM. (2009). "Wnt4 is not sufficient to induce lobuloalveolar mammary development." BMC Dev Biol 9: 55.

Klug DB, Crouch E, Carter C, Coghlan L, Conti CJ, Richie ER. (2000). "Transgenic expression of cyclin D1 in thymic epithelial precursors promotes epithelial and $\mathrm{T}$ cell development." J. Immunol. 164: 1881-1888. 
Kühl M, Geis K, Sheldahl LC, Pukrop T, Moon RT, Wedlich D.(2001). "Antagonistic regulation of convergent extension movements in Xenopus by Wnt/beta-catenin and Wnt/Ca2+ signalling." Mech. Dev. 106: 61-76.

Kvell K, Varecza Z, Bartis D, Hesse S, Parnell S, Anderson G, Jenkinson EJ, Pongracz JE. Wnt4 and LAP2alpha as pacemakers of thymic epithelial senescence. PLoS One. 2010 May 18;5(5):e10701.

Labalette C, Renard CA, Neuveut C, Buendia MA, Wei Y. (2004). "Interaction and functional cooperation between the LIM protein FHL2, CBP/p300, and beta-catenin." Mol. Cell Biol. 24(24): 10689-10702.

Leduc L, Levy E, Bouity-Voubou M, Delvin E. Fetal programming of atherosclerosis: possible role of the mitochondria. Eur J Obstet Gynecol Reprod Biol. 2010 Apr;149(2):127-30.

Lind EF, Prockop SE, Porritt HE, Petrie HT.(2001). "Mapping precursor movement through the postnatal thymus reveals specific microenvironments supporting defined stages of early lymphoid development." J. Exp. Med. 194(2): 127-134.

Liu H, Fergusson MM, Castilho RM, Liu J, Cao L, Chen J, Malide D, Rovira II, Schimel D, Kuo CJ, Gutkind JS, Hwang PM, Finkel T. (2007). "Augmented Wnt Signaling in a Mammalian Model of Accelerated Aging." Science 317(5839): 803-806.

Ljubuncic P, Reznick AZ. "The evolutionary theories of aging revisited-a mini-review." Gerontology. 2009;55(2):205-16.

Luo Q, Kang Q, Si W, Jiang W, Park JK, Peng Y, Li X, Luu HH, Luo J, Montag AG, Haydon RC, He TC. (2004). "Connective tissue growth factor (CTGF) is regulated by Wnt and bone morphogenetic proteins signaling in osteoblast differentiation of mesenchymal stem cells." J Biol Chem 279(53): 55958-68.

Lyons JP, Mueller UW, Ji H, Everett C, Fang X, Hsieh JC, Barth AM, McCrea PD. (2004). "Wnt-4 activates the canonical beta-catenin-mediated Wnt pathway and binds Frizzled-6 CRD: functional implications of Wnt/beta-catenin activity in kidney epithelial cells." Exp Cell Res 298(2): 369-87.

Malbon CC, Wang H, Moon RT. (2001). "Wnt signaling and heterotrimeric G-proteins: strange bedfellows or a classic romance?" Biochem. Biophys. Res. Commun. 287(3): 589-93.

Mandinova A, Kolev V, Neel V, Hu B, Stonely W, Lieb J, Wu X, Colli C, Han R, Pazin MJ, Ostano P, Dummer R, Brissette JL, Dotto GP. (2009). "A positive FGFR3/FOXN1 feedback loop underlies benign skin keratosis versus squamous cell carcinoma formation in humans." J Clin Invest 119(10): 3127-37.

Manley, N. R. (2000). "Thymus organogenesis and molecular mechanisms of thymic epithelial cell differentiation." Sem. Immunol. 12: 421-428.

Mann B, Gelos M, Siedow A, Hanski ML, Gratchev A, Ilyas M, Bodmer WF, Moyer MP, Riecken EO, Buhr HJ, Hanski C. (1999). "Target genes of beta-catenin-T cellfactor/lymphoid-enhancer-factor signaling in human colorectal carcinomas." Proc. Natl. Acad. Sci U.S.A. 96(4): 1603-1608.

Marinova, T. T. (2005). "Epithelial framework reorganization during human thymus involution." Gerontology 51(1): 14-8.

Mercurio S, Latinkic B, Itasaki N, Krumlauf R, Smith JC. (2004). "Connective-tissue growth factor modulates WNT signalling and interacts with the WNT receptor complex." Development 131(9): 2137-47. 
Michie AM, Soh JW, Hawley RG, Weinstein IB, Zuniga-Pflucker JC. (2001). "Allelic exclusion and differentiation by protein kinase C-mediated signals in immature thymocytes." Proc. Natl. Acad. Sci U.S.A. 98(2): 609-614.

Min H, Montecino-Rodriguez E, Dorshkind K. (2006). "Reassessing the role of growth hormone and sex steroids in thymic involution." Clinical Immunology 118(1): 117123.

Mulroy, T., McMahon, J.A., Burakoff, S.J., McMahon, A.P., and Sen, J. (2002). "Wnt-1 and Wnt-4 regulated thymic cellularity." Eur. J. Immunol. 32: 967-971.

Nateri AS, Spencer-Dene B, Behrens A. (2005). "Interaction of phosphorylated c-Jun with TCF4 regulates intestinal cancer development." Nature July, Epub.

Newton, A. (2001). "Protein kinase C: structural and spatial regulation by phosphorylation, cofactors, and macromolecular interactions." Chem. Rev. 101: 2353-2364.

Noordermeer, J. K., J., Perrimon, N., and Nusse, R. (1994). "Dishevelled and armadillo act in the wingless signalling pathway in Drosophila." Nature 367: 80-83.

Oksanen, A. (1971). "Multilocular fat in thymuses of rats and mice associated with thymus involution: a light- and electron-microscope and histochemical study." J Pathol 105(3): 223-6.

Peavy RD, Hubbard KB, Lau A, Fields RB, Xu K, Lee CJ, Lee TT, Gernert K, Murphy TJ, Hepler JR. (2005). "Differential effects of Gq alpha, G14 alpha, and G15 alpha on vascular smooth muscle cell survival and gene expression profiles." Mol Pharmacol. 67(6): 2102-21014.

Pinson, K. I., Brennan, J., Monkley, S., Avery, B.J., Skarnes, W.C. (2000). "An LDL-receptorrelated protein mediates Wnt signalling in mice." Nature 407(6803): 535-538.

Pongracz J, Hare K, Harman B, Anderson G, Jenkinson EJ. (2003). "Thymic epithelial cells provide Wnt signals to developing thymocytes." Eur. J. Immunol. 33: 1949-1956.

Qiao S, Chen L, Okret S, Jondal M. (2008). "Age-related synthesis of glucocorticoids in thymocytes." Exp Cell Res 314(16): 3027-35.

Ribeiro, R. M. and A. S. Perelson (2007). "Determining thymic output quantitatively: using models to interpret experimental T-cell receptor excision circle (TREC) data." Immunol Rev 216: 21-34.

Roman-Roman S, Shi DL, Stiot V, Haÿ E, Vayssière B, Garcia T, Baron R, Rawadi G. (2004). "Murine Frizzled-1 behaves as an antagonist of the canonical Wnt/beta-catenin signaling." J Biol Chem. 279: 5725-5733.

Rosso, S., D. Sussman, et al. (2005). "Wnt signaling through Dishevelled, Rac and JNK regulates dendritic development." Nat. Neuroscience 8: 34-42.

Schluns KS, Cook JE, Le PT. (1997). "TGF-beta differentially modulates epidermal growth factor-mediated increases in leukemia-inhibitory factor, IL-6, IL-1 alpha, and IL-1 beta in human thymic epithelial cells." J Immunol 158(6): 2704-12.

Schwabe RF, Bradham CA, Uehara T, Hatano E, Bennett BL, Schoonhoven R, Brenner DA. (2003). "c-Jun-N-terminal kinase drives cyclin D1 expression and proliferation during liver regeneration." Hepatology 37(4): 824-832.

Seike M, Mizutani H, Sudoh J, Gemma A. (2009). "Epithelial to mesenchymal transition of lung cancer cells." J Nippon Med Sch 76(4): 181.

Sheldahl LC, Slusarski DC, Pandur P, Miller JR, Kühl M, Moon RT. (2003). "Dishevelled activates Ca2+ flux, PKC, and CamKII in vertebrate embryos." J. Cell Biol. 161(4): 767-777. 
Shiraishi J, Utsuyama M, Seki S, Akamatsu H, Sunamori M, Kasai M, Hirokawa K. Essential microenvironment for thymopoiesis is preserved in human adult and aged thymus. Clin Dev Immunol. 2003 Mar;10(1):53-9.

Shtutman M, Zhurinsky J, Simcha I, Albanese C, D'Amico M, Pestell R, Ben-Ze'ev A. (1999). "The cyclin D1 gene is a target of the beta-catenin/LEF-1 pathway." Proc. Natl. Acad. Sci U.S.A. 96(10): 5522-5527.

Smit L, Baas A, Kuipers J, Korswagen H, van de Wetering M, Clevers H. (2004). "Wnt activates the Tak1/Nemo-like kinase pathway." J Biol Chem 279(17): 17232-40.

Staal, F. J. and H. Clevers (2003). "Wnt signaling in the thymus." Curr. Opin. Immunol. 15(2): 204-208.

Staal, F. J. T., Meeldijk, J., Moerer, P., Jay, P., van de Weerdt, B.C.M., Vainio, S., Nolan, G.P., Clevers, H. (2001). "Wnt signaling is required for thymocyte development and activates Tcf-1 mediated transcription." Eur. J. Immunol. 31.: 285-293.

Stahn C, Löwenberg M, Hommes DW, Buttgereit F. (2007). "Molecular mechanisms of glucocorticoid action and selective glucocorticoid receptor agonists." Mol Cell Endocrinol 275(1-2): 71-8.

Talaber G, Kvell K, Varecza Z, Boldizsar F, Parnell SM, Jenkinson EJ, Anderson G, Berki T, Pongracz JE. Wnt-4 protects thymic epithelial cells against dexamethasone-induced enescence. Rejuvenation Res. 2011 Jun;14(3):241-8.

Tamai, K., Semenov, M., Kato, Y., Spkony, r., Chumming, L., Katsuyama, Y., Hess, F., Saintjeannet, J.-P., He, X. (2000). "LDL-receptor-related proteins in Wnt signal transduction." Nature 407: 530-535.

Tanaka Y, Mamalaki C, Stockinger B, Kioussis D. (1993). "In vitro negative selection of alpha beta $\mathrm{T}$ cell receptor transgenic thymocytes by conditionally immortalized thymic cortical epithelial cell lines and dendritic cells." Eur. J. Immunol. 23(10): 2614-2621.

Tetsu, O. and F. McCormick (1999). "Beta-catenin regulates expression of cyclin D1 in colon carcinoma cells." Nature 398(6726): 422-426.

Torres MA, Yang-Snyder JA, Purcell SM, DeMarais AA, McGrew LL, Moon RT. (1996). "Activities of the Wnt-1 class of secreted signaling factors are antagonized by the Wnt-5A class and by a dominant negative cadherin in early Xenopus development." J. Cell Biol. 133(5): 1123-1137.

Valsecchi C, G. C., Ballabio A, Rugarli EI. (1997). "JAGGED2: a putative Notch ligand expressed in the apical ectodermal ridge and in sites of epithelial-mesenchymal interactions." Mech. Dev. 69(1-2): 203-207.

Varecza Z, Kvell K, Talabér G, Miskei G, Csongei V, Bartis D, Anderson G, Jenkinson EJ, Pongracz JE. Multiple suppression pathways of canonical Wnt signalling control thymic epithelial senescence. Mech Ageing Dev. 2011 May;132(5):249-56.

Wang, H. and C. Malbon (2003). "Wnt signaling, Ca2+, and cyclic GMP: visualizing frizzled functions." Science 300: 1529-1530.

Wang Z, Shu W, Lu MM, Morrisey EE.(2005). "Wnt7b activates canonical signaling in epithelial and vascular smooth muscle cells through interactions with Fzd1, Fzd10, and LRP5." Mol. Cell Biol. 25: 5022-5030.

Wehrli, M., Dougan, S.T., Caldwell, K., O'Keefe, L., Schwartz, S., Vaizel-Ohayon, D., Schejter, E., Tomlinson, A., DiNardo, S. (2000). "Arrow encodes an LDL-receptorrelated protein essential for Wingless signalling." Nature 407(6803): 527-530. 
Wharton Jr., K. A., Zimmermann, G., Rousset, R., Scott, M.P. (2001). "Vertebrate proteins related to Drosophila naked cuticle bind dishevelled and antagonize Wnt signaling." Developmental Biology 234: 93-106.

Wiegers GJ, Knoflach M, Böck G, Niederegger H, Dietrich H, Falus A, Boyd R, Wick G. (2001). "CD4(+)CD8(+)TCR(low) thymocytes express low levels of glucocorticoid receptors while being sensitive to glucocorticoid-induced apoptosis." Eur J Immunol 31(8): 2293-301.

Wüst S, van den Brandt J, Tischner D, Kleiman A, Tuckermann JP, Gold R, Lühder F, Reichardt HM. (2008). "Peripheral T cells are the therapeutic targets of glucocorticoids in experimental autoimmune encephalomyelitis." J Immunol 180(12): 8434-43.

Xu Y, Banerjee D, Huelsken J, Birchmeier W, Sen JM. (2003). "Deletion of b-catenin impairs T cell development." Nature Immunol. 4: 1177-1182.

Yamamoto, H., Kishida, S., Kishida, M., Ikeda, S., Takada, S., and Kikuchi, A. (1999). "Phosphorylation of axin, a Wnt signal negative regulator, by glycogen synthase kinase-3beta regulates its stability." EMBO J. 274: 10681-10684.

Yamanaka H, Moriguchi T, Masuyama N, Kusakabe M, Hanafusa H, Takada R, Takada S, Nishida E. (2002). "JNK functions in the non-canonical Wnt pathway to regulate convergent extension movements in vertebrates." EMBO Rep. 3(1): 69-75.

Yan D, Wallingford JB, Sun TQ, Nelson AM, Sakanaka C, Reinhard C, Harland RM, Fantl WJ, Williams LT. (2001). "Cell autonomous regulation of multiple Dishevelleddependent pathways by mammalian Nkd." Proc. Natl. Acad. Sci U.S.A. 98(7): 38023807.

Zhang X, Gaspard JP, Chung DC. (2001). "Regulation of vascular endothelial growth factor by the Wnt and K-ras pathways in colonic neoplasia." Cancer Res. 61(16): 60506054.

Zilberberg A, Yaniv A, Gazit A. (2004). "The low density lipoprotein receptor-1, LRP1, iteracts with the human Frizzled-1 (HFz1) and down-regulates the canonical Wnt signaling pathway." J Biol Chem. 279: 17535-17542. 


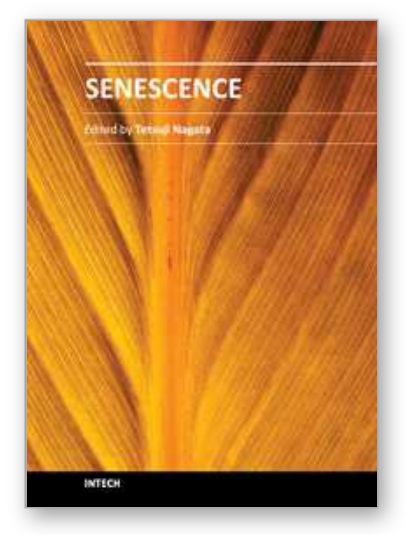

\author{
Senescence \\ Edited by Dr. Tetsuji Nagata
}

ISBN 978-953-51-0144-4

Hard cover, 850 pages

Publisher InTech

Published online 29, February, 2012

Published in print edition February, 2012

The book "Senescence" is aimed to describe all the phenomena related to aging and senescence of all forms of life on Earth, i.e. plants, animals and the human beings. The book contains 36 carefully reviewed chapters written by different authors, aiming to describe the aging and senescent changes of living creatures, i.e. plants and animals.

\title{
How to reference
}

In order to correctly reference this scholarly work, feel free to copy and paste the following:

Krisztian Kvell and Judit E. Pongracz (2012). Central Immune Senescence, Reversal Potentials, Senescence, Dr. Tetsuji Nagata (Ed.), ISBN: 978-953-51-0144-4, InTech, Available from:

http://www.intechopen.com/books/senescence/central-immune-senescence-reversal-potentials

\section{INTECH}

open science | open minds

\section{InTech Europe}

University Campus STeP Ri

Slavka Krautzeka 83/A

51000 Rijeka, Croatia

Phone: +385 (51) 770447

Fax: +385 (51) 686166

www.intechopen.com

\section{InTech China}

Unit 405, Office Block, Hotel Equatorial Shanghai

No.65, Yan An Road (West), Shanghai, 200040, China

中国上海市延安西路65号上海国际贵都大饭店办公楼405单元

Phone: +86-21-62489820

Fax: +86-21-62489821 
(C) 2012 The Author(s). Licensee IntechOpen. This is an open access article distributed under the terms of the Creative Commons Attribution 3.0 License, which permits unrestricted use, distribution, and reproduction in any medium, provided the original work is properly cited. 